\title{
NUMERICAL SIMULATION OF POLLUTANT TRANSPORT FROM FISH FARMING IN RIVER
}

\author{
Tran Thi Ngoc TRIEU1, Le Song GIANG², Minjiao LU3 \\ ${ }^{1}$ Department of Civil and Environmental Engineering, Nagaoka University of Technology, Niigata, Japan \\ 2 Faculty of Civil Engineering, Hochiminh City University of Technology, HCM city, Vietnam \\ ${ }^{3}$ Department of Civil and Environmental Engineering, Nagaoka University of Technology, Niigata, Japan.
}

\begin{abstract}
This paper presented a 3D model for substance transport in river and its application for simulation of pollutant transport in Mekong river due to floating cages-raising. 3D flow-field was solved by logarithmic distributing 2D flow-field of averaged height. Pollutant transport is calculated by solving its full 3D transport equation. The 2D continuum and momentum equations were solved by finite difference method with ADI scheme of Ponce-Yabusaki. The 3D transport equation was solved by finite volume method with ADI scheme of Douglas - Gunn in "sigma" transformed co-ordinate. The model was tested over analytical solution. Some preliminary results of simulation for pollutant transport of Myhoahung floating cages area (Angiang province) are also presented.
\end{abstract}

Key Words : Numerical simulation; floating cages; pollutant transport; finite volume method

\section{INTRODUCTION}

In recent year, with the dramatic increased demand for aquaculture products, the farming of tra and basa fish is one of the fastest growing types of aquaculture in the world. In Vietnam, 1.2 million tons of tra fish were produced in 2007 - a goal the country had set for 2010. This development generates profit and income but it also faces risks of negative environmental impact, such as pollution or biodiversity change.

In order to keep stock density and pollutant loadings lower than environmental capacity, using numerical models is very important for planning and management of fish farming.

Kishi et $a l^{1)}$ developed a numerical model to calculate spatial distribution of COD, DO and deposits from fish aquaculture. Wu et $a l^{2)}$ combined a 2D two layer hydrodynamic model and 3D tidal water quality model which was run to simulate water quality due to $\mathrm{BOD}, \mathrm{NH}_{3}$, DO from marine fish farming. Hevia et $a l^{3)}$ made a model for benthic deposition under fish cages. Doglioli et $a l^{4)}$ developed a numerical model to study dispersion of wastes coming from a marine fish farm in the Ligurian Sea. However, no model has been applied for pollution control from fish farming in river with

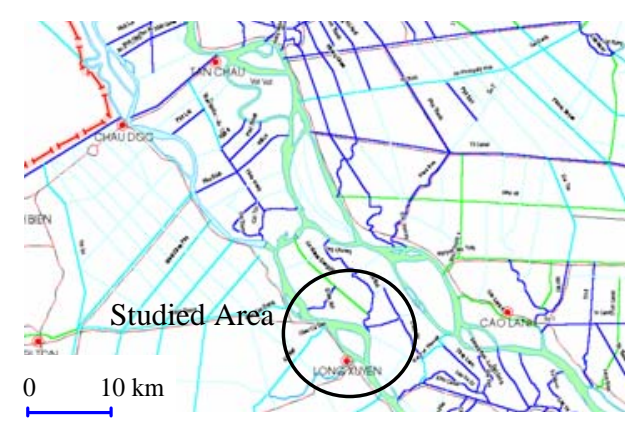

Fig.1 Study area in Longxuyen, Angiang Province, Vietnam

tidal effect in tropical regions. This paper presents a model that applied for simulation of water quality conditions due to specified pollutant loadings from floating cages in Mekong river at Myhoahung fish farm (Longxuyen, Angiang province) where 85\% homemade food is used as feed (Fig. 1). In the model, velocity field was solved in 2D continuum and momentum equations by finite difference method with ADI scheme of Ponce-Yabusaki. Whereas, the pollutant transport was solved in 3D transport equation by finite volume method with ADI scheme of Douglas - Gunn" in "sigma" transformed co-ordinate system. 


\section{NUMERICAL MODEL}

\section{(1) Governing equations}

In the Descartes co-ordinate system, velocities were calculated by $2 \mathrm{D}$ shallow water equations that are written as follows:

$$
\begin{gathered}
\frac{\partial \eta}{\partial t}+\frac{\partial h U}{\partial x}+\frac{\partial h V}{\partial y}=q_{s} \\
\frac{\partial U}{\partial t}+U \frac{\partial U}{\partial x}+V \frac{\partial U}{\partial y}+ \\
F_{x}-M_{x}+g \frac{\partial \eta}{\partial x}=0 \\
\frac{\partial V}{\partial t}+U \frac{\partial V}{\partial x}+V \frac{\partial V}{\partial y}+ \\
F_{y}-M_{y}+g \frac{\partial \eta}{\partial y}=0
\end{gathered}
$$

A logarithmic velocity distribution equation was used to calculate the velocity distributions along the water depth:

$$
\begin{aligned}
& u(x, y, z)=\frac{U}{\left[\frac{z_{0}}{h}-1+\ln \left(\frac{h}{z_{0}}\right)\right]} \ln \frac{z}{z_{0}} \\
& v(x, y, z)=\frac{V}{\left[\frac{z_{0}}{h}-1+\ln \left(\frac{h}{z_{0}}\right)\right]} \ln \frac{z}{z_{0}}
\end{aligned}
$$

$w(x, y, z)$ was calculated from Eq.(6)

$$
\frac{\partial u}{\partial x}+\frac{\partial v}{\partial y}+\frac{\partial w}{\partial z}=0
$$

Then the pollutant concentration $\mathrm{C}$ is solved by: $\frac{\partial C}{\partial t}+\frac{\partial u C}{\partial x}+\frac{\partial v C}{\partial y}+\frac{\partial\left(w-\omega_{s}\right) C}{\partial z}=\frac{\partial}{\partial x}\left(A_{C} \frac{\partial C}{\partial x}\right)$ $+\frac{\partial}{\partial y}\left(A_{C} \frac{\partial C}{\partial y}\right)+\frac{\partial}{\partial z}\left(K_{C} \frac{\partial C}{\partial z}\right)+S$

Where $z_{0}=$ a height with zero velocity; $u, v$ and $w=$ velocity in the $\mathrm{x}, \mathrm{y}, \mathrm{z}$ direction; $A_{C}, K_{C}=$ eddy diffusivity coefficients in horizontal and vertical direction; $\omega_{\mathrm{s}}=$ settling velocity; $S=$ the source term; $U, V=2$ components of depth averaged velocity in $\mathrm{x}, \mathrm{y}$ direction; $t=$ time; $g=$ gravity acceleration; $\eta=$ water surface elevation; $z_{b}=$ bed elevation; $h=\eta-z_{b} ; \rho=$ water density; $q_{s}=$ lateral inflow; $F_{x}, F_{y}=$ external forces of $\mathrm{x}$, y direction.
Eq.(7) was solved with boundary conditions:

\section{a) Free surface boundary}

No pollutant flux goes through the surface:

$$
\left[\omega_{s} C-K_{C} \frac{\partial C}{\partial z}\right]_{\eta}=0
$$

\section{b) Bottom boundary}

At separation of bed layer, the pollutant flux going through the separation was defined as:

$$
\left[\omega_{s} C-K_{C} \frac{\partial C}{\partial z}\right]_{z_{b}+a}=D_{b}-E_{b}
$$

In which: $D_{b}=$ uneaten food, faeces accumulated in the bottom; $E_{b}=$ uneaten food, faeces loaded from bottom. As suggested by Van Rijn ${ }^{6)}$ :

$$
D_{b}-E_{b}=\omega_{s}\left(C_{b}-C_{b^{*}}\right)
$$

In which: $C_{b}, C_{b^{*}}=$ current concentration and saturated concentration in bed surface; As $C_{b^{*}}=7 \mathrm{E}-7 \mathrm{~kg} / \mathrm{m}^{3}$ (Cromey et al $)^{7}$

$$
\left[\omega_{s} C-K_{C} \frac{\partial C}{\partial z}\right]_{z_{b}+a}=\omega_{s}\left(C_{b}-C_{b^{*}}\right)
$$

\section{c) Solid boundary}

The pollutant flux is set to zero.

d) Open boundary

A value of pollutant concentration is defined at the inlet. At outlet boundary: a zero-gradient condition of concentration is used.

\section{(3) Turbulence model}

In the 3D flow of river and ocean, due to a very large difference between quantities specific to motion in horizontal and vertical direction, turbulent viscosity for horizontal and vertical direction was calculated by different models.

Eddy diffusivity coefficient $A_{C}$ was assigned by the horizontal turbulence viscosity coefficient $A_{M}$, calculated by using a model proposed by Smagorinsky ${ }^{8}$ :

$$
A_{M}=C \Delta x \Delta y\left[\left(\frac{\partial u}{\partial x}\right)^{2}+\left(\frac{\partial v}{\partial y}\right)^{2}+\frac{1}{2}\left(\frac{\partial u}{\partial y}+\frac{\partial v}{\partial x}\right)^{2}\right]
$$

Where $C=0.01-0.5$. In this paper, $C=0.10$ was chosen.

Eddy diffusivity coefficient $K_{C}$ was assigned by the vertical turbulence viscosity $K_{M}$ calculated by using the mixing length model of Prandtl-Kolmogorov (1942):

$$
K_{M}=C_{\mu}^{,} L \sqrt{k}
$$

\section{(2) Boundary conditions}




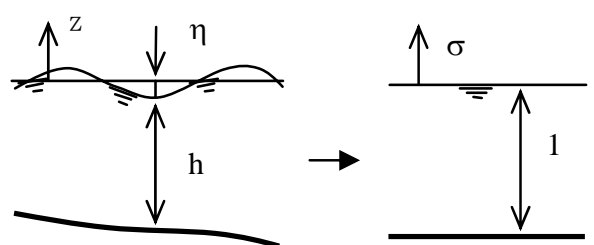

Fig.2 Sigma co-ordinate transformation.

$$
\begin{aligned}
& L=\kappa h(1-\varsigma) \sqrt{\varsigma} \\
& k=\frac{1}{\sqrt{c_{\mu}}}\left[\left(u_{*}^{b}\right)^{2}(\varsigma)+\left(u_{*}^{s}\right)^{2}(1-\varsigma)\right]
\end{aligned}
$$

Where $C^{\prime}{ }_{\mu}=$ model constant; $L=$ mixing length, $k=$ turbulent kinetic energy; $c_{\mu}=0.09$ model constant; $\kappa=0.4$ Von Karman constant; $u_{*}^{s}, u_{*}^{b}=$ shear velocities in free surface and bed surface; $\quad \varsigma=(\eta-z) /(\eta+h)$ relative depth.

\section{(4) Methodology}

Equations were changed to sigma transformed co-ordinate system:

$$
\sigma=\frac{z-\eta}{h+\eta}
$$

In this co-ordinate, calculated domain with free surface and curved bed surface becomes a rectangular prism with the total depth equals to 1 where $\sigma=0$ at water surface and $\sigma=-1$ at bed surface (Fig. 2). It allows to describe more exactly flow and pollutant transport near water and bed surfaces.

Eq.(7) was solved by the finite volume method in alternate grid that was showed in (Fig. 3). The equation was transformed into sigma coordinate.

$$
\begin{aligned}
& \frac{\partial q_{C}}{\partial t}+\frac{\partial}{\partial x}\left(u q_{C}-D A_{C} \frac{\partial}{\partial x}\left(\frac{q_{C}}{D}\right)\right) \\
&+\frac{\partial}{\partial y}\left(v q_{C}-D A_{C} \frac{\partial}{\partial y}\left(\frac{q_{C}}{D}\right)\right)+ \\
& \frac{\partial}{\partial \sigma}\left(\left(\omega-\frac{\omega_{s}}{D}\right) q_{C}-\frac{K_{C}}{D} \frac{\partial}{\partial \sigma}\left(\frac{q_{C}}{D}\right)\right)=D . S
\end{aligned}
$$

In which $D=$ total water depth; $q_{C}=D . C$ pollutant discharge; $\omega=$ vertical velocity in sigma coordinate.

After defining water surface and components of velocity, pollutant concentration is calculated from Eq.(17) by ADI scheme of Douglas - Gunn. Convection terms of pollutant transport equation were interpolated following centered scheme. Because of different wave propagation characteristics, time interval of transport equation was chosen many times larger than that of

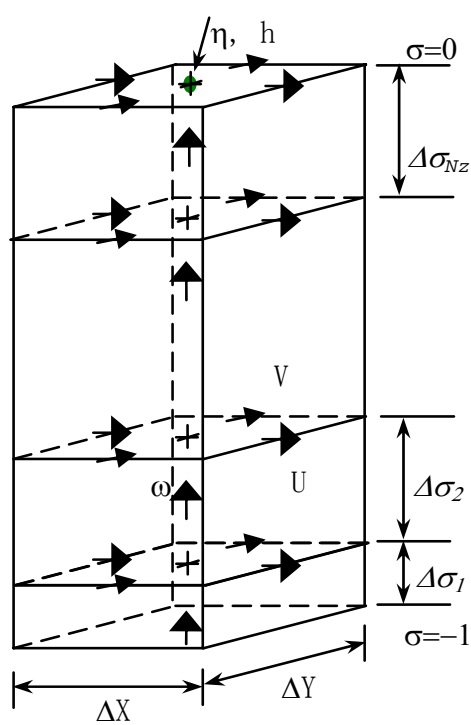

Fig.3 Position of variables in calculated grid.

momentum equations.

\section{RESULTS AND ANALYSIS}

\section{(1) Model was tested over analytic solution}

In flow field assumed $w=v=0, u=$ const, ignored diffusion in $\mathrm{x}$ direction. Exact solution of Eq.(7) for a continuous source with capacity $M$ located at $(x=0, y=0, z=H)$ is:

$$
\begin{array}{r}
C(x, y, z)=\frac{M}{2 \pi U \sigma_{y} \sigma_{z}} E X P\left(-\frac{y^{2}}{2 \sigma_{y}^{2}}\right) \\
E X P\left(-\frac{\left(z-H+W_{s} x / U\right)^{2}}{2 \sigma_{z}^{2}}\right)
\end{array}
$$

Where $\sigma_{y}$ and $\sigma_{z}$ are dispersion coefficients that only vary in $\mathrm{x}$ direction.

$$
\sigma_{y}^{2}=\frac{2 A_{C}}{U} x ; \quad \sigma_{z}^{2}=\frac{2 K_{C}}{U} x
$$

Above solution is formulation of pollutant transport of Gaussian distribution.

A computational domain is chosen with length in $\mathrm{x}$ direction of $1000 \mathrm{~m}$, length in $\mathrm{y}$ direction of $1000 \mathrm{~m}$ and is divided into $100 \times 100$ uniform grid cells, spanning from bed surface, $z_{b}=0$ to $\eta=202.5 \mathrm{~m}$, dividing into 41 layers, thickness of each layer equals to $5 \mathrm{~m}$, only layer that close to bed equals to $2.5 \mathrm{~m}$ in order to raise degree of accuracy. This height is chosen for avoiding effects of topography on simulation. Simulated time is 20 hour with $\Delta t=5 \mathrm{~s}$.

The following are some figures to compare results between numerical solution and analytical solution, unit of contour lines is $\mathrm{g} / \mathrm{l}$.

Pollutant distribution is showed on planes that 


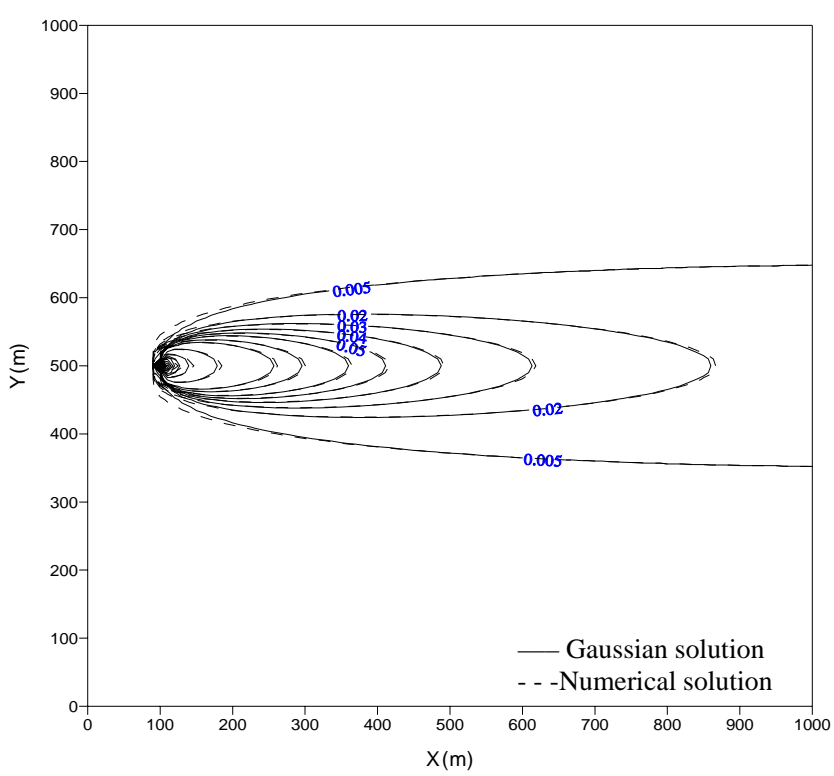

Fig.4 Comparison between numerical solution and analytical solution (XOY)

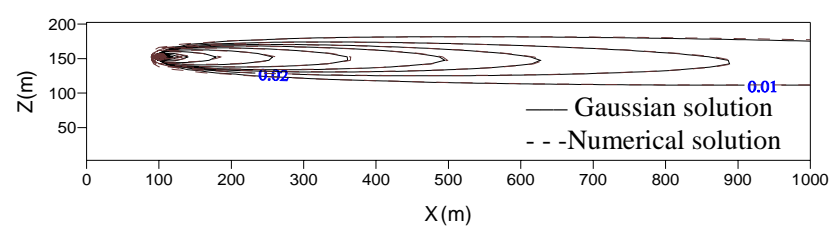

Fig.5 Comparison between numerical solution and analytical solution (XOZ)

cross the source point ( $x=100 \mathrm{~m}, y=500 \mathrm{~m}, z=$ $152.5 \mathrm{~m})$ in the flow direction, with capacity $M=$ $314 \mathrm{~kg} / \mathrm{s}, U=1 \mathrm{~m} / \mathrm{s}, A_{C}=5.0 \mathrm{~m}^{2} / \mathrm{s}, K_{C}=0.5 \mathrm{~m}^{2} / \mathrm{s}$.

The pollutant distribution in $\mathrm{XOY}$ and $\mathrm{XOZ}$ (Fig.4 and Fig.5) planes have good agreement between numerical solution and analytical solution. Only at the source point, pollutant streak in numerical solution has a little spread rearwards against analytical solution because analytical solution does not include diffusion in $\mathrm{x}$ direction.

The largest difference between two solutions of pollutant transport in YOZ plane, at $\mathrm{x}=800 \mathrm{~m}$ (Fig.6) is the pollutant streak of numerical solution being higher than that of analytical solution at free surface boundary.

Through testing by analytical solution, model has good accuracy.

\section{(2) Results of pollutant transport in Hau river Longxuyen section}

The model was applied to Myhoahung fish farm. Dimension of calculated domain is 10000mx5000mx25m, divided into 25mx25m cells in horizontal plane and 10 layers in vertical direction. Only grid cell next to river bed is half height of the above one. Time interval is $\Delta t=1 \mathrm{~s}$ to

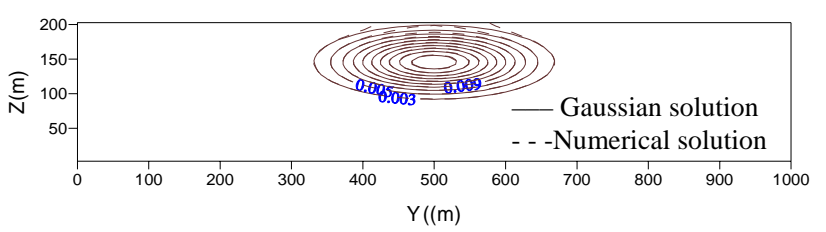

Fig.6 Comparison between numerical solution and analytical solution (YOZ)

Table 1 Pollutant concentration in Myhoahung fish farm

All value are in $\mathrm{mg} / \mathrm{l}$

\begin{tabular}{|c|l|c|c|}
\hline No & \multicolumn{1}{|c|}{ Position } & SS & BOD $_{5}$ \\
\hline 1 & Upstream of fish farm (right side) & 16 & 4 \\
\hline 2 & Center of fish farm (right side) & 19 & 2 \\
\hline 3 & Downstream of fish farm (right side) & 15 & 3 \\
\hline 4 & Upstream of fish farm (left side) & 29 & 3 \\
\hline 5 & Center of fish farm (left side) & 18 & 3 \\
\hline 6 & Downstream of fish farm (left side) & 22 & 3 \\
\hline 7 & Environmental Standard & 80 & 10 \\
\hline
\end{tabular}

(Sources: Angiang Department of Science and Technology)

ensure stability of model when solving water surface and velocities, time interval for solving transport equation is 30s to speed up calculation.

Simulation is made for dry season from 20:00:00 04/09/2000 to 20:00:00 04/12/2000. A group of 4 cages with dimension $12 \mathrm{mx} 10 \mathrm{mx}$ $4 \mathrm{~m} / 1$ cage located in $3.5-5.0 \mathrm{~m}$ deep, close to the river bank is chosen. Annual output for 2 times of harvest is 400ton fish. Total feed is about 2.13ton/day. Two pollutants are simulated: BOD, suspended solid (uneaten food and faeces) SS.

Case 1: Wimberly ${ }^{9)}$ reported BOD excretion was $0.216 \mathrm{~kg}$ BOD $/ \mathrm{kg}$ feed. In group of cages BOD excretion is $460 \mathrm{~kg} / \mathrm{day}$, with continuous released. Location of source point in $8^{\text {th }}$ layer is $0.8-1.0 \mathrm{~m}$ distant from water surface. Self purification coefficient is $1.15 \mathrm{E}-6 \mathrm{~s}^{-1}$ suggested by Phangsombut ${ }^{10)}$.

In Fig.7 at the first tide, released BOD spreads to upstream during flood tide; until simulated for 6 hours, on ebb tide, streak of BOD is drifted downstream and diffused away, BOD concentration decreases. At $16^{\text {th }}$ hour, in the second tide, BOD streak spreads upstream again. Till ebb tide again at the $24^{\text {th }}$ hour, BOD streak begins to travel downstream, BOD load is more dispersed and diluted due to strong advection by tidal flow. Consequently, maximum BOD at the source point is about $3.0 \mathrm{mg} / \mathrm{l}$. So BOD concentration on cages site is small and below Vietnamese environment standard (Table 1). Maximum flow velocity in this time is $0.5 \mathrm{~m} / \mathrm{s}$. In dry season, BOD concentration in fish farming impacts locally and no considerable effect to water quality because of large river, faster 


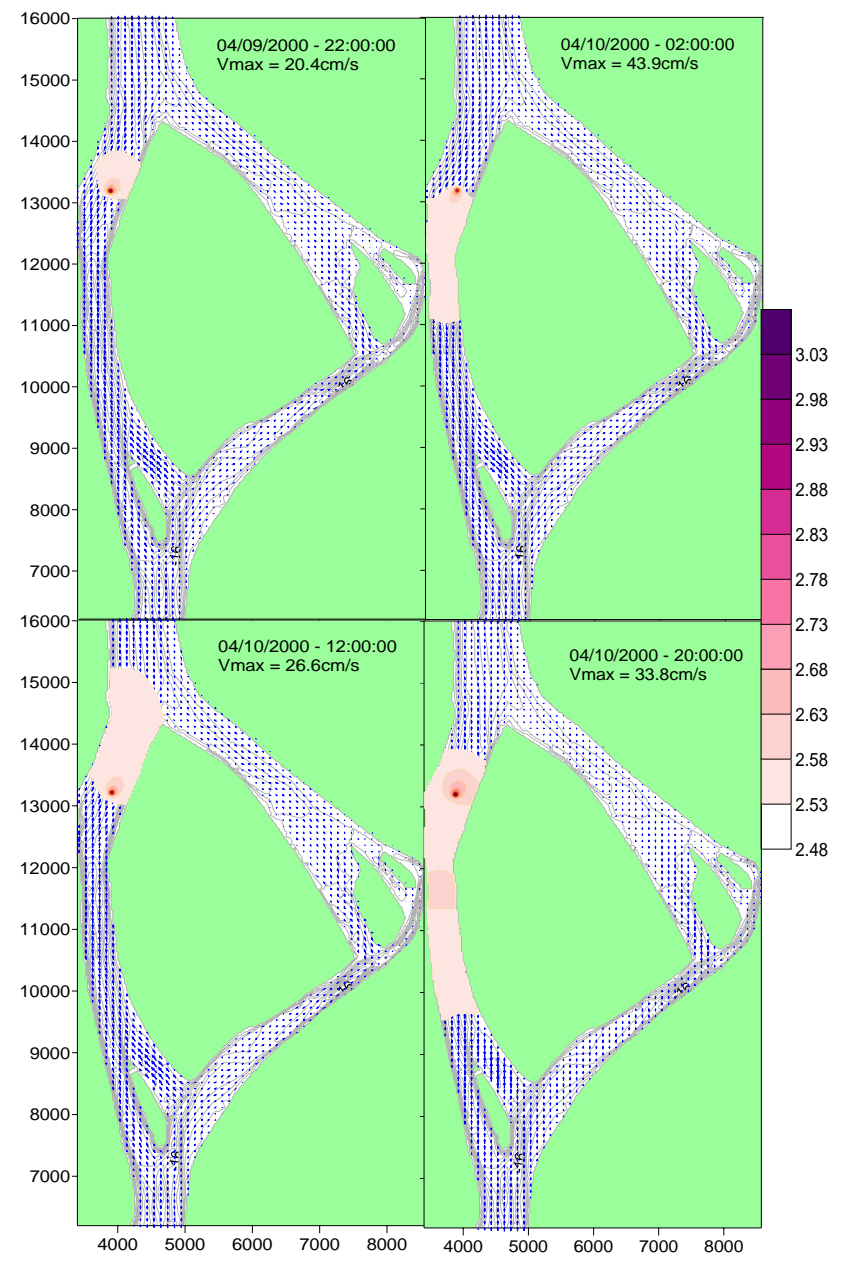

Fig.7 Process of BOD transport in 24hours with tidal effects

current movements. Besides diffusion, self purification capability also plays a big role to minimize the degree of pollution.

Case 2: In order to model the wastage rates of fish feed and faeces (SS), we can choose between several types of expressions. The first one was given empirically by Liao and $M^{111)}$ : $S S=(0.52) F$ where $S S$ is suspended solids production ( $\mathrm{kg} \mathrm{SS} /((100 \mathrm{~kg}$ fish)day) and $\mathrm{F}$ is the feeding rate $(\mathrm{kg}$ food $/((100 \mathrm{~kg}$ fish $)$ day $)$. Total SS amount is $1103 \mathrm{~kg} /$ day. Location of source point in $8^{\text {th }}$ layer is $0.8-1.0 \mathrm{~m}$ distant from water surface. The settling velocity is $0.05 \mathrm{~m} / \mathrm{s}$ given by Elberizon et $a l^{12)}$.

In this case, faeces is assumed $60 \%$ SS to be released continuously over a 24 hour period while feed waste is $40 \% \mathrm{SS}$ released when feeding fish (2-3/times/day), each time takes about 45 minutes. Because pellet food is rarely used here, and food is primary made from trash fish and broken rice, bran..., suspended food is high. In Fig.8, due to SS is not only dispersed in horizontal plane but also settled in vertical direction so transport time is more quickly while its distance is shorter than those of

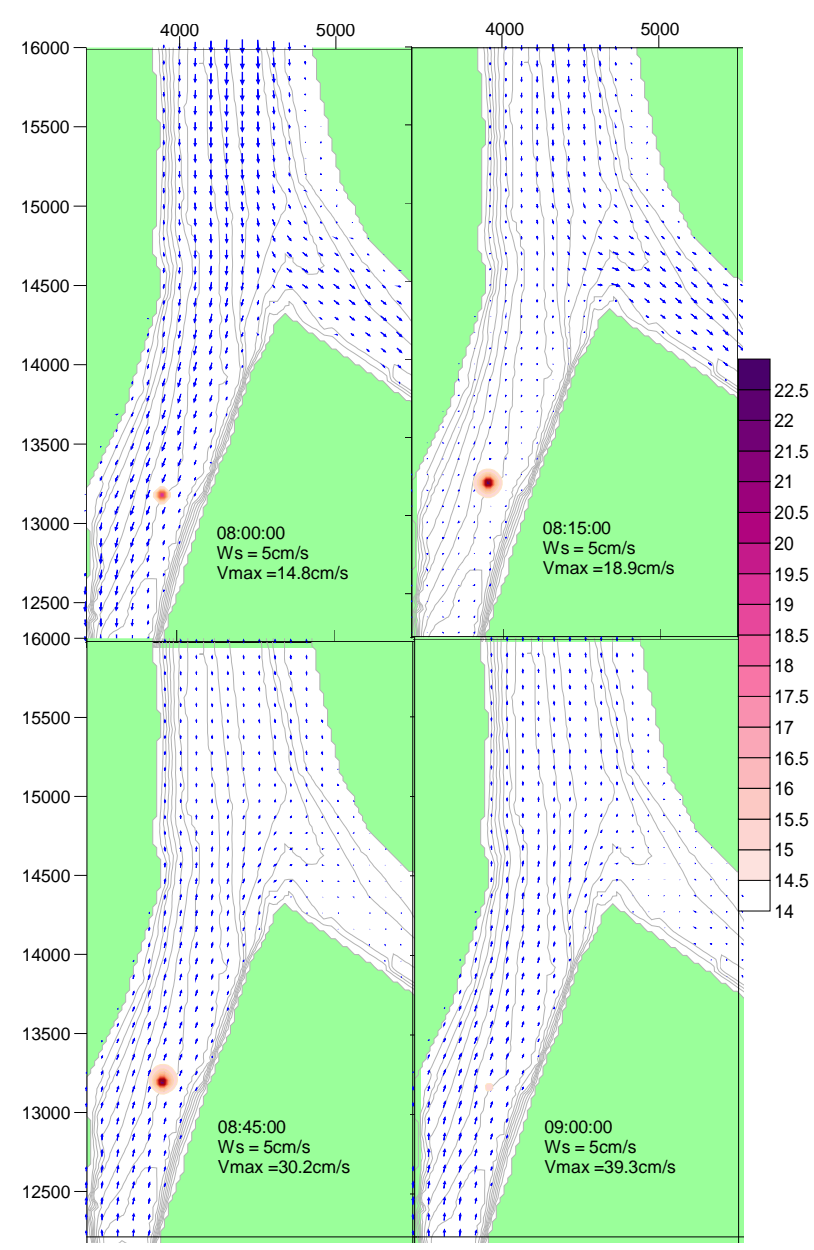

Fig.8 Process of SS transport in feeding and after 15 minutes, 30 minutes, 60 minutes

BOD.

The excess feed and faeces from the fish are dispersed on the riverbed under the cages. They are settled some distance from the farm about $100 \mathrm{~m}$ to $150 \mathrm{~m}$. Our study is about their distribution, not about their influence on the sedimentation and accumulation of organic material under and near the fish cages. In Fig.9 maximum SS concentration in source point when feeding is $23 \mathrm{mg} / \mathrm{l}$. After SS mass settle totally in the river bed, SS concentration in bed changes from $16 \mathrm{mg} / \mathrm{l}$ to $14 \mathrm{mg} / \mathrm{l}$ when feeding is over. So pollution from aquaculture activities has not got an alarming level and does not make serious effect to water quality.

In case of particle material, transport properties are similar to soluble material but there is settling. In vertical planes crossing source point (Fig.10), time varying settling process is showed more clearly.

In this study, owning to numerical simulation, the propagation of pollution along the river as well as distribution of uneaten food over riverbed is understood. Hence, it is easy to assess water quality and also to carry out pollution management. 


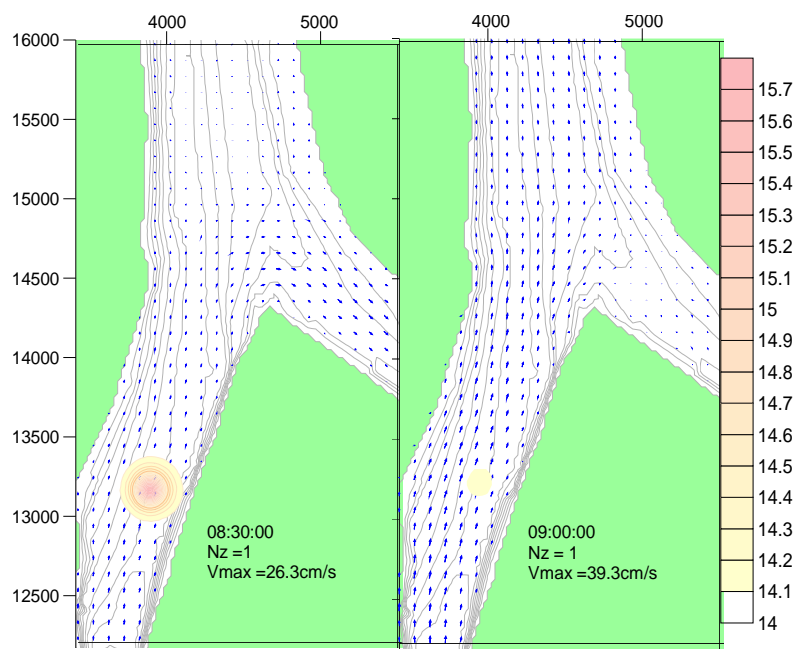

Fig.9 Process of SS distribution in river bed.

\section{CONCLUSION}

The paper presented an effective model for assisting fish farm management. The model can be used as a tool to simulate hydrodynamics and pollutant transport for both soluble and particle wastes. Simulation of the area extent of waste dispersion and loading can be used to determine the location of farms, production levels and the proximity of cage flotillas. Tested over with analytical solution shows that model has a good accuracy. Though having not enough data to compare, simulation results of BOD and uneaten food transport in Myhoahung fish farm are fairly reasonable.

\section{REFERENCES}

1) Kishi, M. J., Uchiyama, M. and Iwata, Y.: Numerical simulation model for quantitative management of aquaculture, Ecological modeling, Vol.72, pp.21-40, 1994.

2) Wu, R. S. S., Shin, P. K. S., MacKay, D. W., Mollowney, M. and Johnson, D.: Management of marine fish farming in the sub-tropical environment: a modeling approach, $2^{\text {nd }}$ Aquaculture, Vol.174, pp. 279-289, 1999.

3) Hevia, M., Rosenthal, H. and Gowen, R. J.: Modelling benthic deposition under fish cages. J.Appl. Ichthyol, Vol.12, pp.71-74, 1996.

4) Doglioli, A. M., Magaldi, M. G., Vezzulli, L. and Tucci, S.: Development of a numerical model to study the dispersion

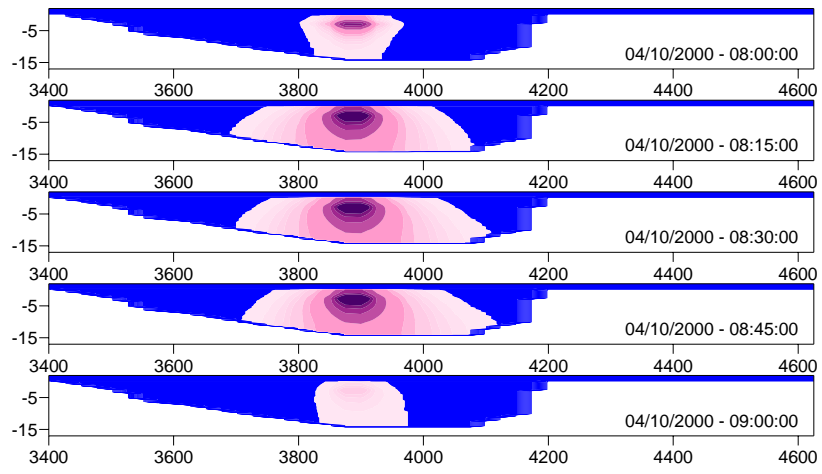

Fig.10 Process of SS transport when feeding in vertical plane

of wastes coming from a marine fish farm in the Ligurian Sea, Aquaculture, Vol.231, pp.215-235, 2004.

5) Douglas, J. J. and Gunn, J. E.: A general formulation of alternating direction methods - Part I. parabolic and hyperbolic problems, Num. Math, Vol.6, pp. 428-453, 1964.

6) Van Rijn.: Mathematical modelling of morphological processes in the case of suspended sediment transport, Delft Hydraulics Communication No.382, 1987.

7) Cromey, C. J., Nickell, T. D., Black, K. D., Provost, P. G. and Griffiths, C. R.: Validation of a fish farm waste resuspension model by use of a particulate tracer discharged from a point source in a coastal environment, Estuaries, Vol.25, No.5, pp. 916-929, 2002.

8) Smagorinsky, J.: General circulation experiments with the primitive equations. I: The basic experiment. Monthly Weather Review, Vol.91, pp. 99-164, 1963.

9) Wimberly, D. M.: Development and evaluation of a low-density media biofiltration unit for use in recirculating fish culture systems. Master thesis. Louisiana State University, Baton Rouge, Louisiana, USA, 1990.

10) Phangsombut, P.: Self purification capacity of the rangtubbtap canal, Sanutsongkram Province. Master thesis, 2005.

11) Liao, P. B. and Mayo, R. D.: Intensified fish culture combining water reconditioning with pollution abatement, Aquaculture, Vol.3, pp. 61-85, 1974.

12) Elberizon, I. and Kelly, L.: Settling measurements of parameters critical to modelling benthic impacts of freshwater salmonid cage aquaculture, Aquaculture Research, Vol.29, pp. 669-677, 1998.

(Received September 30, 2010) 